\title{
Penerapan Model Pembelajaran Kooperatif Tipe STAD dan Tipe GI Terhadap Hasil Belajar IPA Siswa Pada Materi Pencemaran Lingkungan
}

\author{
Agnes Inka Christy Ogi ${ }^{*}$, Fransiska Harahap ${ }^{2}$ \\ 1,2 Jurusan Pendidikan IPA, FMIPA, Universitas Negeri Manado \\ *e-mail: agnesicogi@gmail.com
}

\begin{abstract}
Abstrak. Hasil wawancara di SMP Negeri 9 Dumoga ditemukan bahwa dalam proses pembelajaran IPA, cara guru menyampaikan materi masih berpusat pada guru atau kurang melibatkan siswa serta kurangnya penggunaan variasi model dalam proses pembelajaran sehingga membuat siswa kurang aktif. Oleh karena itu proses pembelajaran belum terlaksana secara optimal dan hasil belajar IPA siswa belum mencapai nilai KKM. Penelitian ini bertujuan untuk mengetahui apakah ada perbedaan hasil belajar antara siswa yang diajarkan dengan model pembelajaran kooperatif tipe STAD dan siswa yang diajarkan dengan model pembelajaran GI pada materi pencemaran lingkungan di SMP Negeri 9 Dumoga. Penelitian ini menggunakan desain penelitian nonequivalent control group design. Pengambilan sampel dilakukan dengan teknik sampling jenuh dan diperoleh 2 kelas dengan jumlah masing-masing 20 siswa, kelas VIIA sebagai kelas eksperimen I dan kelas VIIB sebagai kelas eksperimen II. Data hasil belajar siswa dari kedua model pembelajaran diperoleh dari pretest dan posstest. Hasil penelitian menunjukkan bahwa pada uji hipotesis (uji-t) diperoleh nilai signifikan $0,015<0,05$ maka $\mathrm{H}_{0}$ ditolak dan $\mathrm{H}_{1}$ diterima. Sehingga disimpulkan bahwa terdapat perbedaan hasil belajar siswa, baik yang diberi model pembelajaran STAD dan yang diberi model pembelajaran GI untuk materi pencemaran lingkungan pada kelas VII di SMP Negeri 9 Dumoga.
\end{abstract}

Kata kunci: student teams achievement division, group investigation, hasil belajar, pencemaran lingkungan

\begin{abstract}
The results of interviews at SMP Negeri 9 Dumoga found that in the science learning process, the way the teacher delivered the material was still teacher-centred or less involving students and the lack of use of various models in the learning process so that students were less active. Therefore, the learning process has not been implemented optimally and students' science learning outcomes have not reached the KKM value. This study aims to determine whether there are differences in learning outcomes between students who are taught the STAD type cooperative learning model and students who are taught the GI learning model on environmental pollution material at SMP Negeri 9 Dumoga. This study used a nonequivalent control group design. Sampling was carried out using saturated sampling technique and obtained 2 classes with a total of 20 students each, class VIIA as experimental class I and class VIIB as experimental class II. Data on student learning outcomes from the two learning models were obtained from the pretest and posttest. The results showed that the hypothesis test ( $t$-test) obtained a significant value of $0.015<0.05$, so $H_{0}$ was rejected and $H_{1}$ was accepted. So it was concluded that there were differences in student learning outcomes, both those given the STAD learning model and those given the GI learning model for environmental pollution material in class VII at SMP Negeri 9 Dumoga.
\end{abstract}

Keywords: student teams achievement division, group investigation, learning outcomes, environmental pollution 


\section{PENDAHULUAN}

Proses pembelajaran merupakan salah satu bagian dari pendidikan. Setiap guru atau pendidik menginginkan proses pembelajaran yang dilaksanakannya menyenangkan, menarik minat dan perhatian siswa, serta dapat meningkatkan hasil belajar siswa setelah mengikuti proses pembelajaran. Namun, untuk melakukan hal tersebut, masih ada saja hambatan atau kendala yang dialami guru untuk memperoleh hasil belajar siswa yang baik dan optimal.

Kendala pada proses pembelajaran disebabkan pembelajaran masih berpusat pada guru, sehingga membuat siswa kurang aktif, cepat merasa bosan, dan tidak tertarik untuk belajar. Salah satu cara yang dapat dilakukan oleh guru agar proses pembelajaran dapat terlaksana dengan baik, yakni guru harus mampu memahami karakteristik serta kebutuhan siswa, dan lingkungan belajarnya, agar dapat mempertimbangkan model pembelajaran yang tepat digunakan, serta sesuai dengan materi yang akan dipelajari. Karena penggunaan model pembelajaran yang tepat akan berpengaruh terhadap baik buruknya proses pembelajaran serta hasil belajar peserta didik.

Adapun model pembelajaran yang dapat memicu partisipasi aktif serta interaksi siswa dalam proses pembelajaran adalah dengan kerjasama kelompok. Salah satu jenis model pembelajaran yang melibatkan siswa belajar secara berkelompok atau bekerjasama dalam kelompok kecil yaitu model pembelajaran kooperatif.

Penggunaan model pembelajaran yang dititik beratkan pada perencanaan kooperatif siswa di dalam menyelidiki dan mengidentifikasi suatu permasalahan secara bersama di dalam suatu kelompok belajar, serta membutuhkan kerjasama untuk mencapai tujuan bersama dan mengkoordinasikan usahanya untuk menyelesaikan tugas serta memperoleh penghargaan kooperatif, adalah model pembelajaran kooperatif tipe Student Teams Achievement Division (STAD) dan tipe Group Investigation (GI) (Santoso \& Rintayati, 2017).
STAD merupakan salah satu model yang bertujuan untuk memotivasi siswa agar saling mendukung dan membantu satu sama lain dalam menguasai kemampuan yang diajarkan oleh guru. Ada beberapa sintaks dari model STAD yang terdiri dari penyajian kelas, kelompok, kuis, skor kemajuan individual, dan yang terakhir rekognisi tim (Slavin, 2008).

Menurut Herdian (dalam Esminarto, Sukowati, Suryowati, \& Anam, 2016) keunggulan model STAD yakni semua anggota kelompok wajib mendapat tugas, ada interaksi langsung antar siswa dan siswa dengan guru, siswa dilatih untuk mengembangkan keterampilan sosial, mendorong siswa untuk menghargai pendapat orang lain, dapat meningkatkan kemampuan akademik siswa dan melatih siswa untuk berani bicara di depan kelas.

GI merupakan suatu model pembelajaran aktif dimana pada investigasi dan mempresentasikan laporan hasil investigasi siswa harus bekerja sama dengan anggota kelompoknya (Suryanda, Azrai, \& Wari, 2016). Adapun langkah-langkah model investigasi kelompok menurut Trianto (dalam Tumanan, 2019), yaitu memilih topik/ pengelompokan, perencanaan cooperative, implementasi, analisis dan sintesis, presentasi hasil, dan yang terakhir yaitu evaluasi. Adapun keunggulan model pembelajaran GI yaitu melibatkan peserta didik sejak perencanaan, baik dalam menentukan topik maupun cara untuk mempelajarinya melalui investigasi, selain itu model ini menuntut para peserta didik untuk memiliki kemampuan yang baik dalam berkomunikasi maupun dalam keterampilan proses kelompok (Sugandi, 2017).

Hasil wawancara di SMP Negeri 9 Dumoga ditemukan bahwa dalam proses pembelajaran IPA, cara guru menyampaikan materi masih berpusat pada guru atau kurang melibatkan siswa serta kurangnya penggunaan variasi model dalam proses pembelajaran. Hal ini membuat siswa kurang aktif dan cepat merasa bosan. Oleh karena itu proses pembelajaran belum terlaksana secara 
optimal dan hasil belajar IPA siswa belum mencapai nilai Kriteria Ketuntasan Minimal (KKM), dimana siswa yang belum mencapai KKM sebanyak 70\% nilai siswa berkisar antara 40-45. Nilai KKM di SMP Negeri 9 Dumoga khususnya pada mata pelajaran IPA adalah 75 .

Solusi permasalahan yang terdapat dalam proses pembelajaran di SMP Negeri 9 Dumoga berupa penerapan model pembelajaran kooperatif tipe STAD dan tipe GI terhadap hasil belajar ipa siswa pada materi pencemaran lingkungan. Penelitian ini bertujuan untuk mengetahui perbedaan hasil belajar IPA siswa yang diajarkan dengan model pembelajaran kooperatif tipe STAD dan siswa yang diajarkan dengan model pembelajaran kooperatif tipe group investigation pada materi pencemaran lingkungan.

\section{METODE PENELITIAN}

Penelitian ini dilaksanakan di SMP Negeri 9 Dumoga pada bulan januarifebruari 2021 yaitu pada semester genap tahun ajaran 2020/2021. Dimana seluruh populasi digunakan sebagai sampel dalam penelitian ini, yaitu kelas VII A dan kelas VII B, dan teknik pengambilan sampel yang digunakan yaitu teknik sampling jenuh.

Jenis penelitian ini adalah penelitian eksperimen semu (quasi experimental) dengan menggunakan nonequivalent control group design, dimana dalam desain ini terdapat dua kelompok atau dua kelas, yang diambil menggunakan teknik sampling jenuh. Dua kelas tersebut diberi pretest, treatment dan posttest, kelas pertama disebut dengan kelas eksperimen I dan kelas kedua disebut kelas eksperimen II, seperti yang dapat dilihat pada Tabel 1.

Tabel 1. Desain penelitian nonequivalent control group design

\begin{tabular}{llll}
\hline Kelas & Pretest & Treatment & Posttest \\
\hline Eks I & $\mathrm{O}_{1}$ & $\mathrm{X}_{1}$ & $\mathrm{O}_{2}$ \\
Eks II & $\mathrm{O}_{3}$ & $\mathrm{X}_{2}$ & $\mathrm{O}_{4}$ \\
\hline
\end{tabular}

Berdasarkan Tabel 1, menunjukkan Eks I sebagai kelas eksperimen I, Eks II sebagai kelas eksperimen II, $\mathrm{O}_{1}$ sebagai pretest untuk kelas eksperimen I, $\mathrm{O}_{2}$ sebagai posttest untuk kelas eksperimen I, $\mathrm{O}_{3}$ sebagai pretest untuk kelas eksperimen II, $\mathrm{O}_{4}$ sebagai posttest untuk kelas eksperimen II, $\mathrm{X}_{1}$ sebagai perlakuan dengan menggunakan model pembelajaran STAD dan $\mathrm{X}_{2}$ sebagai perlakuan dengan menggunakan model pembelajaran GI.

Variabel dalam penelitian ini dibedakan menjadi 3 yaitu: 1) variabel bebas yakni model pembelajaran kooperatif tipe STAD dan GI yang digunakan pada kelas eksperimen I dan II; 2) variabel terikat yakni hasil belajar pencemaran lingkungan pada siswa kelas VII SMP Negeri 9 Dumoga; 3) variabel kontrol yakni guru, alokasi waktu, dan materi yang diajarkan. Dalam penelitian ini, peneliti bertindak sebagai guru pada kedua kelas eksperimen. Waktu pembelajaran serta materi yang diajarkan untuk kedua kelas eksperimen adalah sama.

Instrumen yang digunakan dalam penelitian ini terdiri dari 2 instrumen, yaitu: 1) instrumen pembelajaran yang meliputi RPP dan LKS, 2) instrumen pengambilan data meliputi intrumen tes berupa soal uraian atau essay, untuk memperoleh hasil belajar siswa.

Untuk teknik pengumpulan data dalam penelitian ini menggunakan tes, dimana tes yang digunakan berupa pretest dan posttest dengan bentuk soal essay, untuk memperoleh hasil belajar siswa pada materi pencemaran lingkungan. Sedangkan untuk teknik analisis data peneliti menggunakan bantuan program komputer SPSS versi 21, dengan langkah pertama yaitu uji instrumen test meliputi uji validitas dan reliabilitas, kemudian uji prasyarat hipotesis meliputi uji normalitas dan homogenitas dan yang terakhir uji hipotesis (uji-t).

Hipotesis dalam penelitian ini dihitung menggunakan rumus uji-t yaitu $\mathrm{t}=\frac{\overline{\mathrm{X}_{1}}-\overline{\mathrm{X}_{2}}}{\sqrt{\frac{\mathrm{s}_{1}^{2}}{n_{1}}+\frac{\mathrm{s}_{2}^{2}}{n_{2}}}} \quad$ (Sugiyono, 2015). Dengan kriteria pengujian hipotesis, yaitu tolak $\mathrm{H}_{0}$ jika sig < 0,05. Namun, dalam pengujian hipotesis dengan menggunakan 
program komputer SPSS versi 21 dengan kriteria pengujian uji hipotesis (uji-t) yaitu: 1) nilai signifikan $>0,05$ maka ratarata hasil belajar IPA siswa sama (terima $\mathrm{H}_{0}$ ); 2) nilai signifikan $<0,05$ maka ratarata hasil belajar IPA siswa tidak sama atau berbeda (terima $\mathrm{H}_{1}$ ) (Riadi, 2016).

\section{HASIL DAN PEMBAHASAN \\ Hasil Penelitian}

Data dalam penelitian ini diambil di SMP Negeri 9 Dumoga tahun ajaran 2020/2021. Sampel penelitian diambil dari kelas VII yang terdiri dari dua kelas yang masing-masing berjumlah 20 siswa. Data yang diambil adalah hasil belajar siswa dengan memberikan pretest dan posttest pada kelas eksperimen I dan kelas eksperimen II.

Hasil pretest digunakan untuk menguji normalitas dan homogenitas suatu data untuk memastikan bahwa kedua kelompok eksperimen tersebut berawal dari kondisi yang sama. Sedangkan hasil pretest dan posttest yaitu nilai selisih akan digunakan untuk uji homogenitas (uji-t) untuk mengetahui apakah terdapat perbedaan hasil belajar siswa yang menggunakan model pembelajaran STAD dan GI pada materi pencemaran lingkungan.

Hasil analisis pretest dan posttest dari kelas eksperimen I dan kelas eksperimen II, dapat dilihat pada Tabel 2.

Tabel 2. Deskriptif data pretest dan posttest eksperimen I dan eksperimen II

\begin{tabular}{lllllll}
\hline \multicolumn{5}{c}{ STAD } & \multicolumn{5}{c}{ GI } \\
\cline { 2 - 7 } & $\begin{array}{l}\text { Pre } \\
\text { test }\end{array}$ & $\begin{array}{l}\text { Post } \\
\text { test }\end{array}$ & Selisih & $\begin{array}{l}\text { Pre } \\
\text { test }\end{array}$ & $\begin{array}{l}\text { Post } \\
\text { test }\end{array}$ & Selisih \\
\hline Range & 20 & 20 & 20 & 20 & 20 & 20 \\
Min & 46 & 27 & 31 & 23 & 27 & 27 \\
Max & 73 & 100 & 42 & 69 & 96 & 38 \\
Mean & 59, & 88, & 29,35 & 58, & 82, & 24,00 \\
Std. & 15 & 50 & & 60 & 60 & \\
Devition & 8,26 & 8,26 & 6,56 & 7,44 & 8,22 & 6,65 \\
Varians & 68, & 68, & \multirow{2}{*}{43,08} & 55, & 67, & \multirow{2}{*}{44,31} \\
\hline
\end{tabular}

Berdasarkan Tabel 2, dapat dilihat bahawa selisih rata-rata untuk kelas eksperimen I (STAD) sebesar 29,35 dan untuk kelas eksperimen II (GI) sebesar 24,00 .
Untuk melihat apakah terdapat perbedaan hasil belajar siswa yang diajar dengan menggunakan model pembelajaran STAD dan hasil belajar siswa yang diajar dengan menggunakan model pembelajaran GI, maka dilakukan uji hipotesis atau uji-t. Hasil uji-t dapat dilihat pada Tabel 3.

Tabel 3. Hasil uji-t

\begin{tabular}{llr}
\hline Levene's test for & Selisih & \\
equality of & $F$ &, 020 \\
variances & Sig &, 888 \\
\hline & $T$ & 2,559 \\
& Df & 38 \\
& Sig. &, 015 \\
& (2-tailed) & \\
t-test for & Mean & 5,350 \\
equality of & Difference & \\
means & Std. Error & 2,090 \\
& Difference & \\
\cline { 2 - 3 } & 95\% confidence & Lower \\
& interval of the & 1,118 \\
& difference & Upper \\
& & 9,582 \\
\hline
\end{tabular}

Berdasarkan Tabel 3, dapat dilihat bahwa nilai signifikan (2-tailed) sebesar 0,015 lebih kecil dari 0,05 ( sig < 0,05), berdasarkan kriteria pengujian hipotesis jika nilai signifikan $<0,05$, maka $\mathrm{H}_{0}$ ditolak dan $\mathrm{H}_{1}$ diterima.

\section{Pembahasan}

Berdasarkan hasil pengamatan dalam kegiatan pembelajaran, kelas yang diajarkan dengan model STAD dan GI sudah terlihat dimana siswa mulai berpartisipasi dalam diskusi, saling membantu dalam kerja kelompok, serta mengikuti kegiatan pembelajaran dengan baik. Pada pembelajaran STAD, materi yang dibahas dalam diskusi semua kelompok memperoleh materi yang sama secara keseluruhan. Hal ini menyebabkan sebagian besar siswa lebih mudah dalam menguasai atau memahami materi yang telah dipelajari. Berbeda dengan pembelajaran GI, untuk materi atau topik yang akan dibahas dalam kelompok, setiap kelompok memperoleh topik yang berbeda-beda sehingga membutuhkan waktu yang lebih lama untuk siswa mengusai atau memahami secara keseluruhan materi pembelajaran, hal ini 
membuat siswa lebih cenderung memahami materi yang didiskusikan dalam kelompok mereka masing-masing.

Hal tersebut sesuai dengan penelitian yang dilakukan oleh Bugianto (2008) yang menemukan bahwa penerapan model GI dan STAD berpengaruh terhadap hasil belajar biologi siswa kelas VII. Selain itu, diketahui bahwa model STAD adalah model yang efektif digunakan pada pokok bahasan pengolahan limbah untuk mengatasi pencemaran dan kerusakan lingkungan. Penelitian lainnya juga dilakukan Martiyani (2014), yang menemukan bahwa siswa yang mengikuti pembelajaran menggunakan model pembelajaran kooperatif tipe STAD memiliki nilai rata-rata lebih tinggi dibanding siswa yang mengikuti pembelajaran menggunakan model pembelajaran kooperatif tipe GI.

Selain itu, penelitian Abbas, Tamboto, \& Rooroh (2020), juga menemukan bahwa model STAD lebih baik dari model GI. Hal ini disebabkan pada model pembelajaran STAD, siswa aktif membantu dan memotivasi satu dengan yang lain agar semangat untuk berhasil bersama, aktif berperan sebagai tutor sebaya untuk lebih meningkatkan keberhasilan kelompok, sehingga dapat menciptakan suasana belajar yang menyenangkan, bersemangat, dan tidak membuat siswa mudah merasa jenuh dalam mengikuti kegiatan pembelajaran.

Berdasarkan hasil penelitian yang dilakukan, model pembelajaran STAD lebih cocok diterapkan pada materi pencemaran lingkungan, namun bukan berarti model pembelajaran GI tidak baik atau tidak bisa diterapkan dalam pembelajaran IPA. Hal ini didukung oleh penelitian yang dilakukan Praptiwi \& Handika (2012), yang mengemukakan bahwa terdapat perbedaan prestasi belajar, dimana model GI lebih baik daripada model STAD.

Oleh karena itu, dalam menerapkan suatu model pembelajaran, seorang pendidik atau guru harus mampu dalam memperhatikan jenis materi yang akan diajarkan. Apakah model yang akan kita gunakan itu cocok dengan materi yang akan dipelajari serta sesuai dengan apa yang siswa butuhkan. Apabila model yang kita gunakan itu cocok dan sesuai, maka tujuan dari pembelajaran tersebut dapat tercapai dengan baik.

\section{KESIMPULAN}

Berdasarkan hasil penelitian dan pembahasan, dapat disimpulkan bahwa terdapat perbedaan hasil belajar IPA siswa antara kelas eksperimen I yang menggunakan model pembelajaran STAD dan kelas eksperimen II yang menggunakan model pembelajaran GI pada materi pencemaran lingkungan.

\section{DAFTAR PUSTAKA}

Abbas, S., Tamboto, H., \& Rooroh, A. (2020). Penerapan model pembelajaran kooperatif tipe Student Team Achievement Division (STAD) dan group investigation terhadap hasil belajar siswa kelas $\mathrm{X}$ pada mata pelajaran ekonomi di SMA Negeri 1 Tondano. Jurnal Pendidikan Ekonomi, 5(2), 132-137.

Bugianto, W. (2008). Penerapan model pembelajaran kooperatif dengan metode Student Teams Achievement Divisions (STAD) dan Group Investigation (GI) ditinjau dari kemampuan awal siswa terhadap hasil belajar siswa SMP kelas VII. Skripsi. Universitas Sebelas Maret.

Esminarto, E., Sukowati, S., Suryowati, N., \& Anam, K. (2016). Implementasi model stad dalam meningkatkan hasil belajar siwa. BRILIANT: Jurnal Riset dan Konseptual, 1(1), 16-23.

Martiyani, E. (2014). Pengaruh pembelajaran kooperatif model Student Team Achivement Division (STAD) dan Group Investigation (GI) terhadap hasil belajar siswa ditinjau dari minat belajar siswa pada mata pelajaran IPA (Biologi) kelas VIII SMP Negeri 2 Plupuh. Skripsi. Universitas Muhammadiyah Surakarta.

Praptiwi, P., \& Handhika, J. (2012). Efektivitas metode kooperatif tipe GI dan STAD ditinjau dari kemampuan awal. Jurnal Penelitian Pembelajaran Fisika, 3(1), 41-50. 
Riadi, E. (2016). Statistika Penelitian (Analisis Manual dan IBM SPSS). Yogyakarta: Andi Offset.

Santoso, S., \& Rintayati, P. (2017). Pengaruh penggunaan model pembelajaran kooperatif tipe group investigation dan student team achievement division terhadap berfikir kritis ditinjau dari kreativitas siswa pada materi sebaran barang tambang di Indonesia (eksperimen pada siswa kelas XI SMA Negeri 3 Sragen tahun pelajaran 2016/2017). GeoEco, 3(2), 114-125.

Slavin, R. E. (2008). Cooperative Learning: Teori, Riset dan Praktik. Terjemahan: Narulita, Y. (2015). Bandung: Nusa Media.

Sugandi, M. K. (2017). Penerapan model pembelajaran group investigation terhadap hasil belajar peserta didik pada konsep pencemaran lingkungan. Jurnal Bio Educatio, 2(2), 35-39.

Sugiyono. (2015). Metode penelitian kuantitatif, kualitatif, R\&D. Bandung: Alfabeta.

Suryanda, A., Azrai, E. P., \& Wari, N. (2016). Pengaruh penerapan model pembelajaran Group Investigation (GI) terhadap kemampuan berpikir analisis siswa pada materi pencemaran lingkungan. Biosfer: Jurnal Pendidikan Biologi, 9(2), 37-44.

Tumanan, M. D. (2019). Penerapan model pembelajaran group investigation untuk meningkatkan hasil belajar peserta didik pada pokok bahasan sistem ekskresi manusia kelas VIII di SMP Frater Don Bosco Tomohon. Skripsi. Universitas Negeri Manado. 